06.5;07

\title{
Сквозное концентрационное профилирование гетероструктурных солнечных элементов
}

\author{
(ㄱ Г.Е. Яковлев ${ }^{1}$, И.А. Няпшаев ${ }^{2,3}$, И.С. Шахрай ${ }^{2}$, Д.А. Андроников ${ }^{2}$, В.И. Зубков ${ }^{1}$, Е.И. Теруков ${ }^{1-3}$ \\ ${ }^{1}$ Санкт-Петербургский государственный электротехнический университет „ЛЭТИ“, Санкт-Петербург, Россия \\ ${ }^{2}$ ООО «НТЦ тонкопленочных технологий в энергетике», Санкт-Петербург, Россия \\ ${ }^{3}$ Физико-технический институт им. А.Ф. Иофрфе РАН, Санкт-Петербург, Россия \\ E-mail: geyakovlev@etu.ru
}

Поступило в Редакцию 17 мая 2019 г.

В окончательной редакции 17 мая 2019 г.

Принято к публикации 31 мая 2019 г.

Методом электрохимического вольт-фарадного профилирования исследованы гетероструктурные солнечные элементы на основе монокристаллического кремния. Проанализированы особенности электрохимического вольт-фарадного профилирования современных многослойных гетероструктурных солнечных элементов. Получены профили распределения концентрации основных носителей заряда по всей толщине образцов, в том числе впервые в слоях проводящего оксида индия-олова.

Ключевые слова: электрохимическое вольт-фарадное профилирование, гетероструктурные солнечные элементы, монокристаллический кремний, аморфный кремний.

DOI: 10.21883/PJTF.2019.17.48223.17880

Среди возобновляемых источников энергии фотоэлектрическое преобразование солнечной энергии признано самым перспективным, поскольку на ближайшие тысячелетия солнечная энергия является неисчерпаемым, самым мощным и экологически чистым источником энергии $[1,2]$. Следует отметить, что с 2000 г. мировой рынок солнечных фотоэлектрических систем растет в среднем на $30 \%$ в год [3]. Однако дальнейшее развитие солнечной энергетики требует постоянного совершенствования характеристик фотопреобразовательных устройств, важнейшим параметром которых является эффективность преобразования солнечной энергии КПД фотопреобразователей [4]. Существуют различные пути повышения КПД солнечных элементов, среди которых наиболее перспективным является использование гетероструктурной технологии [5]. Использование материалов с различной шириной запрещенной зоны в многопереходных солнечных элементах позволяет уменьшить потери на термализацию носителей заряда. Также за счет применения гетеропереходов возможно существенное снижение потерь, связанных с поверхностной рекомбинацией.

Для приборов с гетероструктурами в качестве активных элементов особое значение имеют свойства границ раздела последних, которые зачастую играют определяющую роль в работе таких устройств. Дальнейшее совершенствование характеристик гетероструктурных солнечных элементов невозможно без детального анализа процессов, происходящих на границах раздела гетеропереходов. Помимо этого непрерывно возрастают требования к составу примеси и ее распределению. Процессы, используемые для производства этих структур, носят сложный характер, а результаты сильно зависят от чистоты исходных материалов и технологического маршрута изготовления слоев. Поэтому неуклонно ужесточаются и требования к методам контроля распределения примеси и основных носителей заряда как на этапе лабораторной разработки структуры, так и на различных стадиях производства полупроводникового прибора.

Метод электрохимического вольт-фарадного (ECV) профилирования позволяет получить информацию как о распределении примеси, так и о концентрации свободных носителей заряда [6]. ECV-метод входит в стандарты Международной ассоциации поставщиков полупроводниковой промышленности SEMI и успешно применяется для исследования различных полупроводниковых гетероструктур. Если измерение ECV-методом в случае однородно легированных полупроводниковых структур хорошо отработано и представляет собой достаточно рутинную задачу, то при проведении измерений для современных многослойных гетероструктур солнечных элементов, в том числе с просветляющими покрытиями оксида индия-олова (ITO), необходимы тщательный подбор параметров травления и выбор рабочей точки измерения.

Цель настоящей работы - впервые провести измерения профилей распределения концентрации основных носителей заряда в резко неоднородно и разнотипно легированных гетероструктурных многослойных солнечных элементах (НЈТ-элементах) по всей глубине с обеих сторон, в том числе сквозь просветляющие покрытия.

Исследовались двусторонние гетероструктуры с тонкими аморфными и микрокристаллическими слоями, используемые в качестве активных элементов современных фотоэлектрических преобразователей на базе монокристаллического кремния. Схематическое изображение структур представлено на рис. 1. Слои mc-Si $n$-типа проводимости и $\alpha$-Si $p$-типа проводимости, так 
Sample N 1

\begin{tabular}{|lr|}
\hline$n^{+}$-mc-Si & $10 \mathrm{~nm}$ \\
\hline$i$ - $\alpha$-Si & $7 \mathrm{~nm}$ \\
\hline$n$-Si substrate & $180 \mu \mathrm{m}$ \\
\hline$i$ - $\alpha$-Si & $7 \mathrm{~nm}$ \\
\hline$p^{+}-\mathrm{mc}-\mathrm{Si}$ & $15 \mathrm{~nm}$ \\
\hline
\end{tabular}

Sample N 2

\begin{tabular}{|lr|}
\hline ITO & $60 \mathrm{~nm}$ \\
\hline$n^{+}-\mathrm{mc}-\mathrm{Si}$ & $10 \mathrm{~nm}$ \\
\hline$i$ - $\alpha$-Si & $7 \mathrm{~nm}$ \\
\hline$n$-Si substrate & $180 \mu \mathrm{m}$ \\
\hline$i$ - $\alpha$-Si & $10 \mathrm{~nm}$ \\
\hline$p^{+}-\mathrm{mc}-\mathrm{Si}$ & $7 \mathrm{~nm}$ \\
\hline ITO & $100 \mathrm{~nm}$ \\
\hline
\end{tabular}

Рис. 1. Последовательность слоев исследуемых гетероструктур солнечных элементов.

же как и собственные слои аморфного кремния, наносились методом плазмохимического осаждения при температуре $200^{\circ} \mathrm{C}$ за счет разложения $\mathrm{SH}_{4}$ в плазме высокочастотного разряда. Для придания $n$ - и $p$-типа проводимости слои mc-Si и $a$-Si легировались атомами фосфора и бора соответственно. Слои собственного кремния также обеспечивают пассивацию поверхности текстурированной подложки $c$-Si. Для уменьшения рекомбинационных потерь толщина этих слоев в процессе роста задается как можно меньшей, критической величиной при этом выступает толщина, достаточная для формирования гетероперехода. Образцы отличались друг от друга наличием/отсутствием (рис. 1) на поверхности слоев $\mathrm{mc}-\mathrm{Si}$ и $\alpha$-Si прозрачного проводящего оксида индия-олова, играющего роль просветляющего покрытия и проводящего контактного слоя, поскольку латеральная проводимость пленок $\alpha$-Si довольно низка [7]. Более подробное описание структур дано в нашей предыдущей работе [8]. Образец № 2 фактически является реальной работающей структурой в конфигурации так называемого фронтального эмиттера, когда свет заходит в элемент со стороны $p$-слоя.

Измерение профилей распределения концентрации основных носителей заряда по глубине исследуемых гетероструктур проводилось на установке электрохимического вольт-фарадного профилирования ECVPro (Nanometrics) [9]. В качестве электролита для создания выпрямляющего контакта нами использовался водный раствор бифторида аммония $\left(\mathrm{NH}_{4} \mathrm{HF}_{2}\right)$ в концентрации $0.1-0.2 \mathrm{M}$ с добавлением изопропилового спирта (20\% от объема раствора) [10]. Подробное описание методики проведения измерений ECVметодом, а также особенностей, возникающих при измерении структур (в частности, кремниевых) с резко неоднородным профилем легирования, представлено ранее в [6].

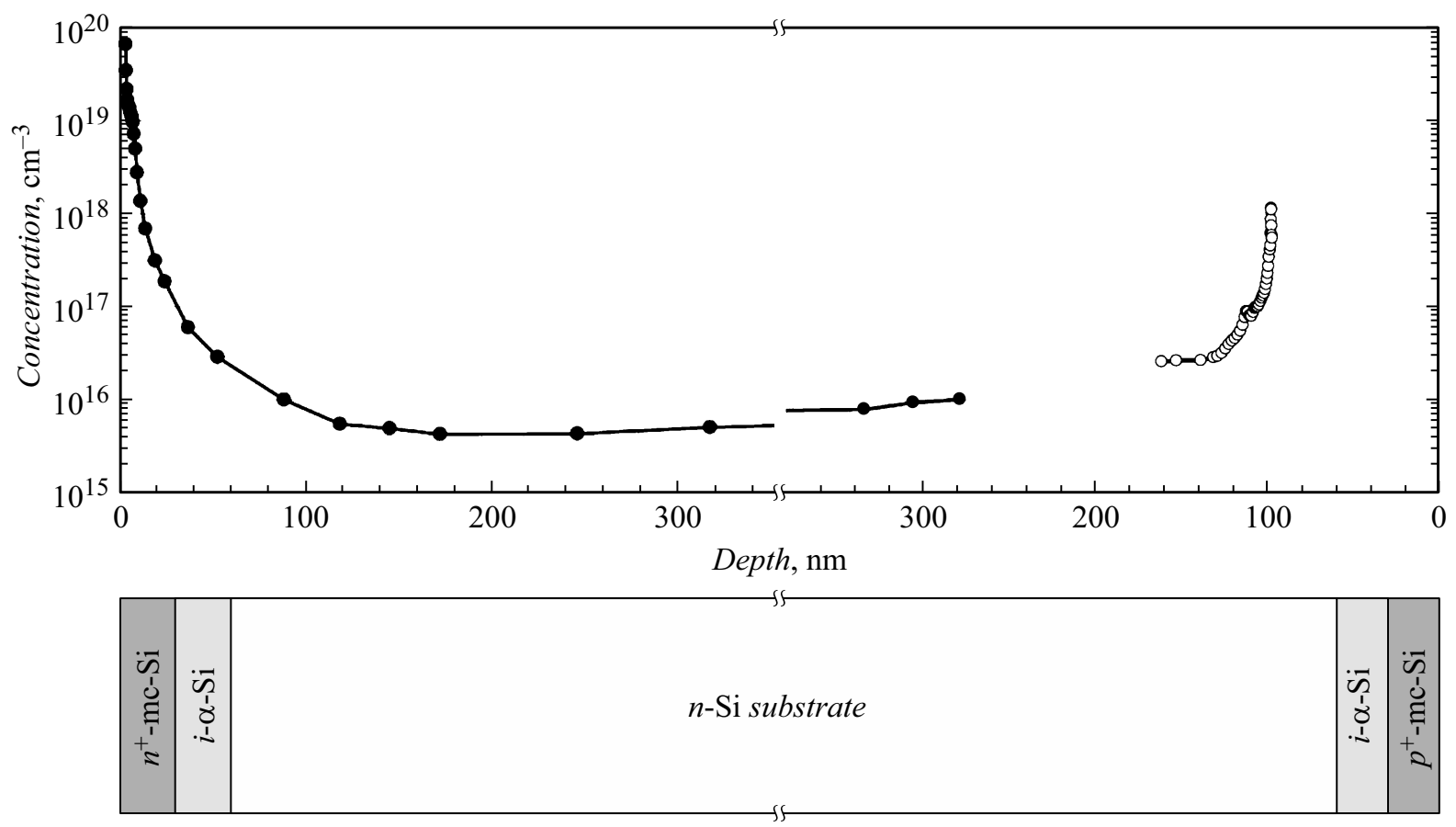

Рис. 2. Наблюдаемый в ECV-эксперименте профиль распределения концентрации ОНЗ по всей глубине тестовой НJTгетероструктуры солнечного элемента (образец № 1). Темные кружки - электроны, светлые — дырки. 

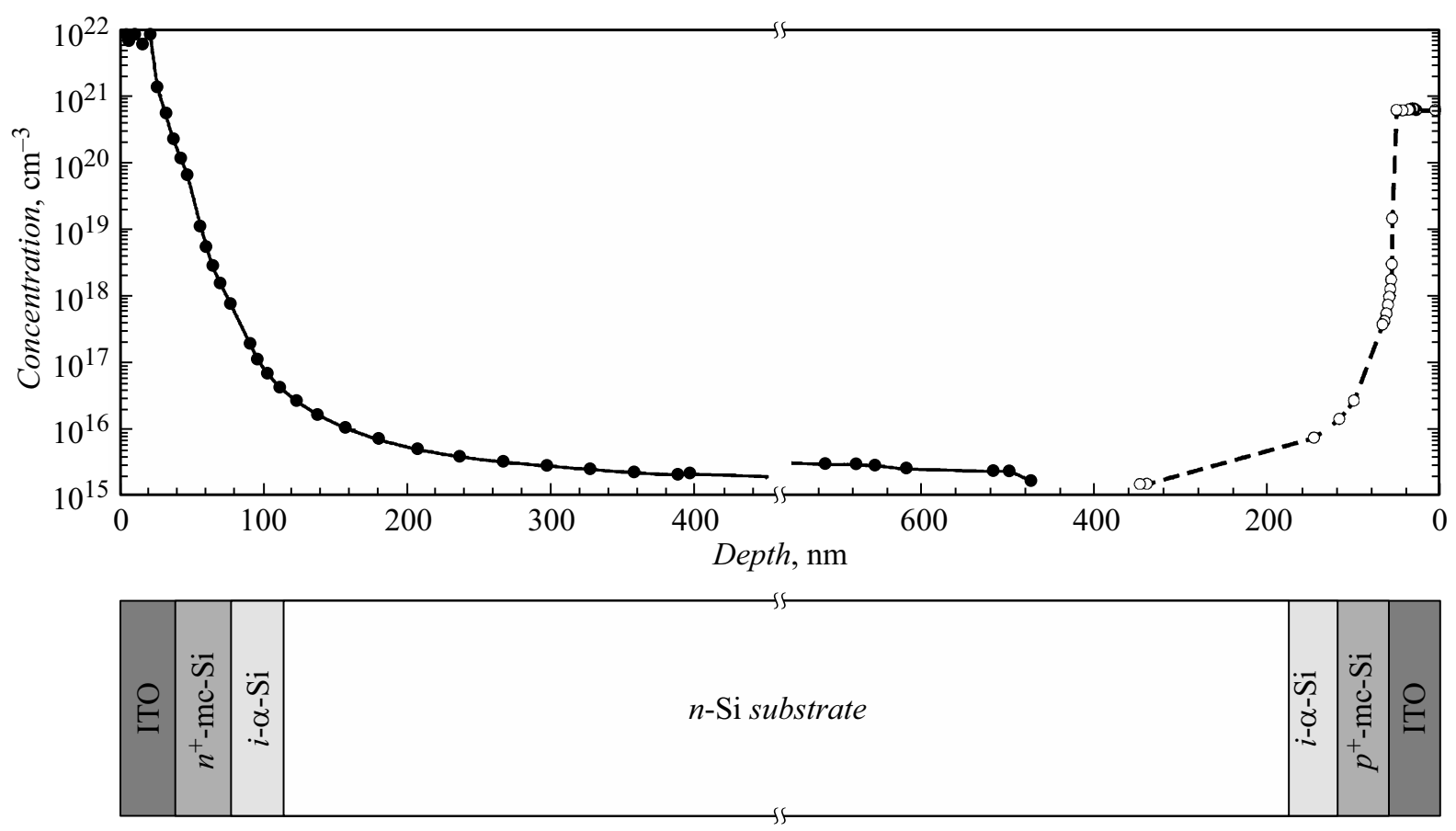

Рис. 3. Наблюдаемый в ECV-эксперименте профиль распределения концентрации ОНЗ по всей глубине приборной НJTгетероструктуры солнечного элемента (образец № 2). Темные кружки - электроны, светлые — дырки.

На рис. 2 показан наблюдаемый профиль распределения концентрации основных носителей заряда (ОН3) для образца № 1. В левой части рисунка приведен профиль распределения концентрации со стороны $n^{+}$-слоя, в правой - со стороны $p^{+}$-слоя. Со стороны $n^{+}$-слоя, как и ожидалось согласно дебаевскому размытию [11], наблюдается монотонное снижение концентрации электронов до значения $\sim 5 \cdot 10^{15} \mathrm{~cm}^{-3}$, соответствующего уровню легирования подложки. Со стороны $p^{+}$-слоя четко зафиксированы $p$ - и $n$-области, а между ними - принципиально не доступная для наблюдения так называемая „слепая зона“ профилирования [11]. Причиной этого является инструментальное ограничение современного емкостного измерительного оборудования. Как видно из рисунка, при данном уровне легирования смежных с металлургической границей $p-n$-перехода областей величина „слепой зоны“ составляет $\sim 100 \mathrm{~nm}$. Следует также отметить, что положение первой точки на экспериментальной зависимости концентрации от глубины в ECV-методе зависит от множества факторов, но в основном определяется шириной встроенной области объемного заряда при данном уровне легирования поверхностного слоя, а также величиной прикладываемого для измерения емкости двухчастотным методом напряжения. Наблюдаемые значения концентрации в подложке, измеренные с двух сторон образца, находятся в хорошей корреляции, что позволяет уверенно заявлять о возможности верификации распределения концентрации ОН3 по всей глубине образца: от поверхности $n$-слоя $\mu \mathrm{m}-\mathrm{Si}$ до поверхности $p$-слоя $\alpha$-Si.
Помимо измерений для тестовых структур были также проведены измерения для реальных приборных гетероструктур. На рис. 3 представлен наблюдаемый профиль распределения концентрации ОНЗ для образца № 2. Особенностью данного образца является наличие на поверхности слоев оксида индия-олова с металлоподобной проводимостью, в частности затрудняющих процесс измерения классическим вольт-фарадным методом. Метод же ECV-профилирования за счет использования электролита в качестве выпрямляющего контакта, а также в качестве материала травителя впервые позволил измерить профиль распределения концентрации в данном материале (ITO), фактически являющемся полуметаллом. Таким образом, в слое ІТО получена концентрация $\sim 10^{22} \mathrm{~cm}^{-3}$ со стороны $n$-слоя и $\sim 6 \cdot 10^{20} \mathrm{~cm}^{-3}$ со стороны $p$-слоя. Сравнение измеренных значений концентрации с литературными оценками показывает схожий порядок концентрации ОНЗ [12-15]. Необходимо заметить, что помимо указанного выше столь большие значения концентрации, как полученные при профилировании структур, не достижимы для других методов измерения концентрации по глубине [7]. Постоянное значение концентрации вблизи поверхности позволяет определить положение гетерограницы между слоем ITO и слоями аморфного полупроводника различного типа проводимости и соответственно толщины слоев ITO. Они составили для $n$-области $35 \mathrm{~nm}$ и для $p$-области $80 \mathrm{~nm}$, что хорошо согласуется с ожидаемыми параметрами структуры. Важно заметить, что ввиду наличия слоев ITO на поверхности, уменьшающих величину 
встроенной области объемного заряда, в отличие от экспериментальных данных для образца № 1 удалось наблюдать первую экспериментальную точку на концентрационном профиле практически у самой поверхности гетероструктуры как со стороны слоев $n$-типа проводимости, так и со стороны слоев $p$-типа проводимости. Как и в случае образца № 1, наблюдается монотонное снижение концентрации ОНЗ в глубь образца (к подложке), характеризуемое дабаевским размытием. Значения концентрации в подложке, измеренные с двух сторон образца, в свою очередь практически идентичны.

Следует также отметить, что при исследовании образца № 2 был применен предложенный нами ранее [9] так называемый метод интеграции вольт-фарадных характеристик. Это дало возможность провести более прецизионные измерения области $p-n$-перехода по сравнению со штатным измерением емкости двухчастотным методом, реализованным в ECV-профилометре, однако, к сожалению, не позволило уменьшить величину упомянутой выше „слепой зоны“.

Таким образом, впервые методом электрохимического вольт-фарадного профилирования удалось получить профили распределения концентрации основных носителей заряда по всей толщине НЈТ-образцов солнечных элементов. Измерения выполнены как на тестовых структурах без покровных слоев ITO, так и на рабочих структурах с двусторонним покрытием ITO. Зарегистрирована концентрация носителей заряда до $10^{22} \mathrm{~cm}^{-3} \mathrm{c}$ $n$-стороны $\left(6 \cdot 10^{20} \mathrm{~cm}^{-3}\right.$ с $p$-стороны), монотонно спадающая на глубине $300 \mathrm{~nm}$ от поверхности до значения $2 \cdot 10^{15} \mathrm{~cm}^{-3}$, соответствующего уровню легирования подложечного материала. Измерения характеризуются высокой воспроизводимостью результатов. Таким образом, данная методика является весьма эффективным способом контроля тестовых структур и готовых приборов солнечной фотоэлектроники. Потенциально применение предложенной методики может позволить более качественно изучить интерфейсы и барьерную структуру между кристаллической подложкой и аморфными/микрокристаллическими собственными и легированными слоями кремния в солнечных элементах НJT. Данные исследования являются весьма актуальными, так как единого фундаментального понимания формирования $p-n$-перехода, энергетических барьеров и разрывов зон в НJТ-элементах в научном мире не достигнуто.

\section{Конфликт интересов}

Авторы заявляют, что у них нет конфликта интересов.

\section{Список литературы}

[1] Delucchi M.A., Jacobson M.Z. // Energy Policy. 2013. V. 39. N 3. P. 1170-1190. DOI: 10.1016/j.enpol.2010.11.045

[2] Husain A., Wan Hasan W.Z., Shafie S., Hamidon M.N., Pandey S.S. // Renew. Sust. Energy Rev. 2018. V. 94. P. 779791. DOI: $10.1016 /$ j.rser.2018.06.031
[3] Shah A. Thin-film silicon solar cells. EPFL Press, 2010. 440 p.

[4] Badawy W.A. // J. Adv. Res. 2015. V. 6. N 2. P. 123-132. DOI: $10.1016 /$ j.jare.2013.10.001

[5] De Wolf S., Descoeudres A., Holman Z.C., Ballif C. // Green. 2012. V. 2. N 1. P. 7-24. DOI: 10.1515/green-2011-0018

[6] Фролов Д.С., Яковлев Г.Е., Зубков В.И. // ФТП. 2019. Т. 53. B. 2. C. 281-286. DOI: 10.21883/FTP.2019.02.47114.8966

[7] Аболмасов С.Н., Абрамов А.С., Иванов Г.А., Теруков Е.И., Емцев К.В., Няпшаев И.А., Базелей А.А., Губин С.П., Корнилов Д.Ю., Ткачев С.В., Ким В.П., Рындин Д.А., Левченкова В.И. // Письма в ЖТФ. 2017. Т. 43. В. 1. С. 74 79. DOI:10.21883/PJTF.2017.01.44092.16380

[8] Terukov E., Kosarev A., Abramov A., Malchukova E. From $11 \%$ thin film to $23 \%$ heterojunction technology (HJT) PV cell: research, development and implementation related $1600 \times 1000 \mathrm{~mm}^{2} \mathrm{PV}$ modules in industrial production // Solar panels and photovoltaic materials / Ed. B. Zaidi. IntechOpen, 2018. P. 62-76. DOI: 10.5772/intechopen.75013

[9] Яковлев Г.Е., Дорохин М.В., Зубков В.И., Дудин А.Л., Здоровейщев А.В., Мальшева Е.И., Данилов Ю.А., Звонков Б.Н., Кудрин А.В. // ФТП. 2018. Т. 52. В. 8. С. 873-880. DOI: $10.21883 /$ FTP.2018.08.46212.8708

[10] Яковлев Г.Е., Фролов Д.С., Зубкова А.В., Зубков В.И., Соломонов А.В., Стерлядкин О.К., Сорокин С.A. // ФТП. 2016. Т. 50. В. 3. С. 324-330. DOI: $10.1134 / \mathrm{S} 1063782616030234$

[11] Yakovlev G., Zubkov V., Solomnikova A., Derevianko O. // Turk. J. Phys. 2018. V. 42. N 4. P. 433-442. DOI: 10.3906/fiz1803-23

[12] Facchetti A., Marks T.J. Transparent electronics: from synthesis to applications. John Wiley and Sons, 2010. 470 p.

[13] Амосова Л.П. // ФТП. 2015. Т. 49. В. 3. С. 426-430. DOI: $10.1134 / \mathrm{S} 1063782615030045$

[14] Balasubramanian N., Subrahmanyam A. // J. Phys. D: Appl. Phys. 1989. V. 22. N 1. P. 206-209. DOI: $10.1088 / 0022-$ 3727/22/1/030

[15] Tahar R.B.H., Ban T., Ohya Y., Takahashi Y. // J. Appl. Phys. 1998. V. 83. N 5. P. 2631-2645. DOI: $10.1063 / 1.367025$ 